\title{
La formación profesional a distancia: nuevos alumnos, nuevos retos
}

\author{
Iris Usach Pérez \\ Profesora asociada del Departamento de Farmacia y Tecnología Farmacéutica y \\ Parasitología de la Facultad de Farmacia de la Universidad de Valencia \\ iris.usach@uv.es \\ Raquel Taléns-Visconti \\ Profesora titular de universidad del Departamento de Farmacia y Tecnología Farmacéutica y \\ Parasitología de la Facultad de Farmacia de la Universidad de Valencia \\ raquel.talens@uv.es \\ Luisa Ruano Casado \\ Profesora titular de universidad del Departamento de Enfermería de la \\ Facultad de Enfermería y Podología de la Universidad de Valencia \\ luisa.ruano@uv.es
}

\section{Extracto}

La implantación de la modalidad semipresencial o a distancia en formación profesional (FP) es relativamente novedosa, existiendo un claro aumento de su demanda en los últimos años. El objetivo de este trabajo fue determinar si existen diferencias en el perfil del estudiante y en su rendimiento académico entre las modalidades a distancia y presencial. Para ello, se realizó un estudio observacional transversal comparativo basado en un análisis de frecuencias. El curso seleccionado fue primero de Emergencias Sanitarias, con 82 alumnos matriculados. Como instrumentos de medida se utilizaron un cuestionario de diseño propio y las actas de evaluación. Los resultados mostraron que el alumnado del grupo semipresencial es de mayor edad, tiene una situación laboral activa, peor disponibilidad, más responsabilidades, mayor interés por el ciclo y, por tanto, mayor motivación. Sin embargo, el alumnado de la modalidad presencial se caracterizó por tener menos responsabilidades, así como un mayor conocimiento de idiomas, y por obtener mejores calificaciones académicas. A pesar de estos resultados, ambas modalidades brindan una formación de calidad y se debe considerar que la enseñanza semipresencial irá adquiriendo más importancia debido a las características de la sociedad actual, sumado a los avances de las tecnologías de la información y la comunicación (TIC).

Palabras clave: educación a distancia; formación profesional (FP); rendimiento académico; tecnologías de la información y la comunicación (TIC).

Fecha de entrada: 22-05-2020 / Fecha de revisión: 11-06-2020 / Fecha de aceptación: 12-06-2020

Cómo citar: Usach Pérez, I., Taléns-Visconti, R. y Ruano Casado, L. (2020). La formación profesional a distancia: nuevos alumnos, nuevos retos. Tecnología, Ciencia y Educación, 17, 5-31. 


\title{
Distance learning in vocational education and training: new students, new challenges
}

\author{
Iris Usach Pérez \\ Raquel Taléns-Visconti \\ Luisa Ruano Casado
}

\section{Abstract}

The implementation of distance learning in vocational education and training (VET) is relatively new, with a clear increase in demand in recent years. The objective of this work was to determine if there are differences in the students' profile and academic performance between traditional and distance learning modes. To do it, a comparative cross-sectional observational study based on a frequency analysis was carried out. 82 students from the first year of Emergency Health Care were enrolled. A self-designed survey and student's grades were used as measuring tools. Results showed that students of the distance group were older, with an active work situation, worse availability, more responsibilities, greater interest in the studies and, therefore, greater motivation. However, students of the face-to-face modality were characterized by having fewer responsibilities as well as a greater knowledge of languages. Finally, academic grades of students enrolled in the face-to-face group were higher. Despite these results, both modalities provide quality training and it should be considered that the distance learning will become more important due to the characteristics of today's society together with the progress of information and communication technologies (ICT).

Keywords: distance learning; vocational education and training (VET); academic achievement; information and communication technologies (ICT). 


\section{Sumario}

1. Introducción

2. Materiales y métodos

2.1. Participantes

2.2. Instrumento

2.3. Procedimiento de recogida y análisis de datos

3. Resultados

3.1. Perfil sociodemográfico de los estudiantes

3.1.1. Distribución por género, edad, estado civil y tipo de domicilio

3.1.2. Distribución según situación laboral y actividades de ocio

3.2. Acceso al ciclo formativo

3.3. Formación académica del alumno

3.3.1. Conocimiento de idiomas

3.3.2. Conocimiento de informática

3.4. Interés por el ciclo formativo

3.4.1. Objetivos que se pretenden conseguir

3.4.2. Interés por los módulos profesionales

3.5. Rendimiento académico

4. Discusión y conclusiones

Referencias bibliográficas

Anexo. Cuestionario 


\section{Introducción}

La notable integración de las TIC en todos los campos está provocando cambios sustanciales en las metodologías de enseñanza-aprendizaje. De hecho, la modalidad de enseñanza online (e-learning), utilizada en la educación a distancia o semipresencial, está presente principalmente en la educación superior y en la FP, pero también en la educación primaria y secundaria (Gros y García-Peñalvo, 2016). Existen cada vez más estudiantes que no pueden asistir a clase por cuestiones de trabajo, responsabilidades familiares, la distancia o los gastos que conlleva la educación tradicional. En estos casos, la educación a distancia es el método más adecuado (Hannay y Newvine, 2006). Varios autores han estudiado las ventajas relacionadas con esta metodología, destacando la gran rentabilidad -consecuencia del ahorro de gastos de desplazamiento y de espacio, ya que ofrece oportunidades de aprendizaje para un gran número de estudiantes sin necesidad de muchos espacios- (Gilbert, 2015; Wheatley y Greer, 1995). Además, con esta metodología, el estudiante consigue un aumento de la satisfacción personal y una disminución del estrés, ya que puede elegir su propio ritmo de aprendizaje y, de esta manera, incrementar su autonomía (Arkorful y Abaidoo, 2015). Asimismo, este tipo de educación ofrece a los estudiantes un recurso fácilmente accesible desde cualquier lugar o ubicación (Hemsley, 2002) y brinda oportunidades a personas con discapacidad (Mikołajewska y Mikołajewski, 2011). Sin embargo, existen estudios que identifican algunos inconvenientes relacionados con la educación online, como la dificultad de compresión de la información más técnica. Por ello, establecen que esta modalidad de enseñanza no puede utilizarse de manera efectiva en áreas científicas que requieren experiencias prácticas (Barker, 1986). Asimismo, la falta de contacto humano no permite a los docentes obtener una retroalimentación durante el proceso de enseñanza-aprendizaje. Por último, cabe destacar que la educación online requiere una motivación muy fuerte, autodisciplina y habilidades de gestión del tiempo para completar el proceso de aprendizaje (Pollard y Hillage, 2001).

En la actualidad, el sistema educativo español permite a los estudiantes elegir la opción de formación más adecuada teniendo en cuenta sus intereses y su situación personal. La FP se centra en carreras basadas en la educación técnica y en la capacitación para el desarrollo de habilidades. Se acerca más a la realidad del mercado laboral y responde a la necesidad de personal cualificado especializado en diferentes sectores profesionales, 
teniendo en cuenta la demanda actual de empleo. En este sentido, la FP mejora la calidad del trabajo y la productividad (Pema y Mehay, 2012). Se trata de una educación cada vez más atractiva, innovadora y dinámica. Así, el número de estudiantes matriculados en ciclos formativos medios y superiores presenciales ha aumentado notablemente en los últimos 10 años. De hecho, del curso académico 2007-2008 al 2017-2018, la matrícula ha pasado de 451.541 a 667.984 estudiantes (Ministerio de Educación y Formación Profesional, Subdirección General de Estadística y Estudios, 2009, 2019). Sin embargo, España es uno de los países de la Organización para la Cooperación y el Desarrollo Económicos (OCDE) con una de las tasas más bajas de participación en la FP. Por ello, las reformas educativas de los últimos 30 años, introducidas por la Ley orgánica de ordenación general del sistema educativo (LOGSE) de 1990 y por la Ley orgánica de educación (LOE) de 2006, han tenido como objetivo mejorar la imagen de la formación profesional en España (Merino y Llosada, 2007). Tradicionalmente, ha existido una imagen devaluada de la FP, asociándola a los alumnos que no sirven para estudiar o no quieren hacerlo, evitando así matricularse en la universidad (Merino, García, Casal y Sánchez, 2011). Sin embargo, actualmente, estos prejuicios negativos están desapareciendo. En este sentido, diversos estudios concluyen que la FP ha dejado de ser un ciclo terminal, ya que los jóvenes no la consideran una alternativa a la universidad, sino una modalidad distinta de formación, a veces complementaria (Planas, 2012). De hecho, cada vez existen más estudiantes que utilizan sus ciclos como vía de acceso a la universidad (Ibarz, Planas, Fachelli, Navarro y Sánchez, 2012) y titulados universitarios que acceden a los ciclos de FP como vía de especialización o complemento posterior a su titulación universitaria.

\section{La FP ha dejado de ser un ciclo terminal, ya que los jóvenes no la consideran una alternativa a la universidad, sino una modalidad distinta de formación, a veces complementaria}

Respecto a la opción de formación, la FP semipresencial o a distancia se define como la modalidad pedagógica que combina contenidos de carácter presencial con otros de carácter no presencial. Así, existen determinados módulos profesionales que, por sus características eminentemente prácticas, requieren asistencia presencial en el centro docente (tutorías colectivas) y actividades de autoaprendizaje del alumnado. Los módulos profesionales de cada título de FP que requieren presencialidad, así como el límite máximo de horas presenciales exigible en la Comunidad Valenciana, se establecen en la Resolución de 22 de mayo de 2018 de la Dirección General de Formación Profesional y Enseñanzas de Régimen Especial (Conselleria de Educación, Investigación, Cultura y Deporte, 2018), siendo dicho porcentaje el $20 \%$ del horario del módulo profesional. Cabe mencionar, además, que la modalidad a distancia ha aumentado considerable-

La modalidad de FP a distancia ha aumentado considerablemente su matrícula en los últimos 10 años mente su matrícula en los últimos 10 años (curso 2007-2008 a 2017-2018), pasando de 10.951 a 75.190 alumnos, es decir, se ha incrementado siete veces (Ministerio de Educación y Formación Profesional, Subdirección General de Estadística 
y Estudios, 2009, 2019). Estos datos demuestran que el e-learning ha adquirido particular importancia en el contexto de la FP, ya que la formación flexible permite una mejor adaptación a los diferentes perfiles de estudiantes que optan por este enfoque de aprendizaje (García, González, García y Rodríguez, 2008).

Como se ha mencionado, en la modalidad e-learning tiene una gran importancia metodológica el uso de las distintas TIC, los recursos que proporciona internet, así como la utilización de materiales didácticos específicos para el autoaprendizaje. Por ello, la correcta utilización de una plataforma software de aprendizaje es imprescindible en esta modalidad pedagógica. A este respecto, el Gobierno promueve y desarrolla, en colaboración con las comunidades autónomas, las plataformas de FP a distancia. Actualmente, la plataforma e-learning más utilizada en España es Moodle (Felpeto-Guerrero, Rey-Iglesia, FernándezVázquez y Garrote-Yáñez, 2015). Su creador, Martin Dougiamas, basó su diseño en las ideas del constructivismo, que afirman que el conocimiento se construye en la mente del estudiante, en lugar de ser transmitido sin cambios a partir de libros o enseñanzas, y en el aprendizaje colaborativo (Chirino, 2008). Moodle es el acrónimo de modular object-oriented dynamic learning enviroment (en español, entorno modular de aprendizaje dinámico orientado a objetos). La primera versión de Moodle apareció en agosto de 2002 y, en la actualidad, se utiliza en 231 países e incluye más de 103.000 sitios registrados en todo el mundo (Moodle, 2019).

Aunque desde 2006 la LOE regula las enseñanzas y su ordenación, a día de hoy todavía existen títulos antiguos, denominados títulos LOGSE. Las principales modificaciones que introdujo la LOE en la FP fueron la duración de los ciclos formativos de grado medio (CFGM) y de los ciclos formativos de grado superior (CFGS), que pasaron de tener una duración de entre 1.000-2.000 horas a ser todos de 2.000 horas; la existencia de un proyecto final; la introducción de los módulos Inglés Técnico y Empresa e Iniciativa Emprendedora; y el incremento de las horas de formación y orientación laboral con el fin de que los alumnos obtengan el título de Técnico en Prevención de Riesgos Laborales a nivel básico. En este contexto, el título de Técnico en Emergencias Sanitarias es un título nuevo (LOE) que pertenece a la familia profesional de sanidad. Se trata de un CFGS que consta de 14 módulos profesionales, además de la formación en centros de trabajo. Por lo que se refiere a la presencialidad requerida en la modalidad semipresencial o a distancia de este título, la normativa instaurada en la Comunidad Valenciana establece la necesidad de presencialidad en cinco de estos módulos (Conselleria de Educación, Investigación, Cultura y Deporte, 2018).

Desde su implantación en España en el curso académico 1993-1994, en el que se registraron un total de 1.229 alumnos, hasta ahora, existe un aumento continuo del número de alumnos que eligen la modalidad e-learning en la formación profesional (García y Cabero, 2016). De hecho, en la Comunidad Valenciana hay 14 ofertas de FP en el sector de la salud y el $85,7 \%$ de ellas también se ofrecen como aprendizaje a distancia o semipresencial. Debido a la importancia que está adquiriendo esta modalidad, el objetivo de este estudio ha 
sido determinar si existen diferencias en el perfil de los estudiantes y en su rendimiento académico entre los entornos de aprendizaje tradicionales y virtuales o a distancia. Para ello se ha utilizado el CFGM Emergencias Sanitarias, partiendo de la hipótesis de que el alumnado de la modalidad semipresencial o a distancia es probablemente de mayor edad, compagina el estudio con su trabajo, el cual suele estar relacionado con el ciclo formativo, y tiene más responsabilidades, por lo que puede dedicarle menos tiempo a los estudios, aunque cabe esperar que muestre mayor capacidad de esfuerzo e interés.

\section{Materiales y métodos}

\subsection{Participantes}

En la investigación han participado un total de 82 estudiantes, todos ellos matriculados en el primer curso académico del ciclo formativo Emergencias Sanitarias de un centro integrado público de FP de la Comunidad Valenciana. Puesto que la finalidad de este trabajo es realizar un estudio comparativo de los alumnos matriculados en la modalidad presencial y en la semipresencial o a distancia, dichos alumnos estaban matriculados en una de las dos modalidades. Cabe señalar que el número de estudiantes participantes de cada modalidad ha sido distinto: 57 alumnos de la modalidad semipresencial y 25 alumnos de la modalidad presencial.

\subsection{Instrumento}

Se ha realizado un estudio observacional transversal comparativo para llevar a cabo la investigación. El instrumento de medida utilizado con el fin de realizar una comparación del perfil del alumnado fue un cuestionario ad hoc anónimo de diseño propio tras la realización de una prueba piloto con una pequeña muestra de estudiantes (véase el anexo situado al final del artículo). Dicho cuestionario consistía en 13 preguntas de opción múltiple, la mayoría de respuesta única, aunque también se incluía alguna de respuesta múltiple. Mediante este cuestionario se valoraron las siguientes variables: género, edad, estado civil, tipo de domicilio, situación laboral, aficiones, conocimiento de idiomas, uso de las TIC, modo y motivo de acceso, expectativas e interés por los módulos profesionales. Para su elaboración se hizo uso de una herramienta de Google destinada a crear formularios -Google Forms-, la cual permite ver los resultados en línea ya graficados o descargarlos en una hoja de cálculo para su posterior análisis. Por otra parte, el instrumento de medida utilizado para comparar el rendimiento académico fueron las actas de evaluación. Las calificaciones numéricas se clasificaron según el sistema educativo español en suspenso $(0-4,9)$, aprobado $(5-6,9)$, notable $(7-8,9)$, sobresaliente $(9-9,9)$ y matrícula de honor (10). 


\subsection{Procedimiento de recogida y análisis de datos}

El procedimiento de cumplimentación de los cuestionarios fue distinto en ambos grupos. El alumnado de la modalidad semipresencial lo contestó de forma online, a través de un enlace disponible en la plataforma virtual Moodle, permaneciendo el documento abierto durante dos meses. Los datos obtenidos se exportaron directamente a una hoja de cálculo en Google Drive. En cambio, a los alumnos de la modalidad presencial se les repartió el cuestionario impreso en papel dentro del horario lectivo y en presencia de la profesora responsable. Posteriormente, los resultados se introdujeron en una hoja de cálculo para su tratamiento. Para realizar la comparación de los perfiles, se analizaron los datos obtenidos mediante los cuestionarios expresados en forma de porcentajes con el fin de lograr una interpretación más clara y directa de los resultados. La representación gráfica de los resultados se realizó mediante el software Microsoft Excel.

Por lo que se refiere a la comparación del rendimiento académico, cabe señalar que el ciclo formativo en la modalidad presencial está estructurado en tres evaluaciones (diciembre, marzo y junio). En cambio, la modalidad semipresencial presenta tan solo dos evaluaciones (enero y mayo). Debido a esta temporalización, los datos utilizados para la comparación fueron los correspondientes a la media aritmética de la primera y la segunda evaluación, en la modalidad presencial, frente a los obtenidos en la primera evaluación de la modalidad semipresencial. Al igual que en el caso anterior, los datos se analizaron mediante un análisis de frecuencias. Para ello, se elaboró una tabla de distribución de frecuencias agrupadas en intervalos (suspenso, aprobado, notable, sobresaliente y matrícula de honor) y se representaron gráficamente los resultados mediante el software Microsoft Excel.

\section{Resultados}

\subsection{Perfil sociodemográfico de los estudiantes}

\subsubsection{Distribución por género, edad, estado civil y tipo de domicilio}

La información de este apartado se muestra de forma resumida en el cuadro 1. En lo relativo a la distribución por género, la mayor parte de los alumnos matriculados en ambas modalidades de este ciclo formativo fueron hombres. Cabe señalar que el porcentaje de mujeres matriculadas en la modalidad presencial fue el doble que en la modalidad semipresencial ( $24 \%$, frente a $12 \%$, respectivamente). Respecto a la edad, existe una diferencia considerable entre ambas modalidades. En concreto, el número de alumnos con un rango de edad de 16-23 años fue muy superior en la modalidad presencial. Además, en la modalidad semipresencial, el $64 \%$ del alumnado era mayor de 32 años, mientras que en el grupo presencial tan solo lo era un $24 \%$. 
Las mayores diferencias según el estado civil se encontraron en el porcentaje de casados, siendo el doble en el grupo semipresencial que en el presencial (32\%, frente a 16\%, respectivamente).

En cuanto al tipo de domicilio de los estudiantes durante el curso, se observó que la mayor parte del alumnado semipresencial poseía domicilio propio (67\%), mientras que para la mayoría de los estudiantes del grupo presencial el domicilio era el paterno (56\%).

\section{Cuadro 1. Perfil sociodemográfico de los estudiantes}

\section{Género}

\begin{tabular}{|c|c|c|}
\hline Femenino & $24 \%$ & $12 \%$ \\
\hline Masculino & $76 \%$ & $88 \%$ \\
\hline \multicolumn{3}{|c|}{ Rango de edad (años) } \\
\hline $16-23$ & $36 \%$ & $4 \%$ \\
\hline $24-31$ & $40 \%$ & $32 \%$ \\
\hline $32-39$ & $8 \%$ & $37 \%$ \\
\hline$>40$ & $16 \%$ & $27 \%$ \\
\hline \multicolumn{3}{|l|}{ Estado civil } \\
\hline Soltero & $80 \%$ & $64 \%$ \\
\hline Casado & $16 \%$ & $32 \%$ \\
\hline Divorciado & $4 \%$ & $4 \%$ \\
\hline \multicolumn{3}{|l|}{ Domicilio } \\
\hline Propio & $32 \%$ & $67 \%$ \\
\hline Paterno & $56 \%$ & $27 \%$ \\
\hline Piso compartido & $8 \%$ & $6 \%$ \\
\hline Hostal/Pensión & $4 \%$ & $0 \%$ \\
\hline
\end{tabular}

Fuente: elaboración propia. 


\subsubsection{Distribución según situación laboral y actividades de ocio}

Por lo que respecta a la situación laboral, se observó una gran diferencia entre ambas modalidades. El porcentaje de personas activas fue muy superior en la modalidad semipresencial que en la presencial ( $67 \%$, frente a $8 \%$, respectivamente). Tan solo un $5 \%$ del alumnado semipresencial se definió como estudiante, frente a un $32 \%$ registrado en el grupo presencial. El resto, un $28 \%$, en el caso de la modalidad semipresencial, y un $60 \%$, en la modalidad presencial, estaban desempleados.

Además, en el caso del alumnado activo, se obtuvo información sobre la jornada laboral que cumplía. En el grupo semipresencial, un $58 \%$ señaló una jornada laboral a turnos; un $24 \%$, continua; un $13 \%$, partida; un $2,5 \%$, reducida; y otro $2,5 \%$, nocturna. En cambio, en el grupo presencial se registró un $50 \%$ de alumnos con jornada reducida y otro $50 \%$ con jornada a turnos.

Por último, se determinó el porcentaje de alumnos activos cuyo trabajo estuviera relacionado con los estudios de Emergencias Sanitarias. En la modalidad semipresencial, un $68 \%$ de alumnos confirmaron su relación con el ciclo formativo, mientras que en la modalidad presencial el resultado fue un $50 \%$.

Con el fin de establecer posibles diferencias basadas en el tipo de alumnado matriculado, se comparó, además, la frecuencia en la realización de distintas actividades de entretenimiento en ambos grupos. Los resultados obtenidos se recogen en los cuadros 2 y 3.

Cuadro 2. Frecuencia de realización de las diferentes actividades de ocio en la modalidad semipresencial

\begin{tabular}{|l|c|c|c|c|c|}
\hline & Nunca & $\begin{array}{c}\text { Esporádi- } \\
\text { camente }\end{array}$ & $\begin{array}{c}\text { Una vez } \\
\text { por semana }\end{array}$ & $\begin{array}{c}\text { Varias veces } \\
\text { por semana }\end{array}$ & Diariamente \\
\hline Reuniones con amigos & $0 \%$ & $28 \%$ & $53 \%$ & $19 \%$ & $0 \%$ \\
\hline Visitas culturales & $9 \%$ & $62 \%$ & $7 \%$ & $2 \%$ & $0 \%$ \\
\hline Pasear & $2 \%$ & $21 \%$ & $11 \%$ & $51 \%$ & $16 \%$ \\
\hline Practicar deportes & $7 \%$ & $21 \%$ & $11 \%$ & $47 \%$ & $14 \%$ \\
\hline Viajar & $4 \%$ & $89 \%$ & $4 \%$ & $2 \%$ & $2 \%$ \\
\hline Ir al cine & $14 \%$ & $75 \%$ & $9 \%$ & $2 \%$ & $0 \%$ \\
\hline Ir al teatro & $58 \%$ & $39 \%$ & $0 \%$ & $2 \%$ & $0 \%$ \\
\hline
\end{tabular}




\begin{tabular}{|l|c|c|c|c|c|}
\hline & Nunca & $\begin{array}{c}\text { Esporádi- } \\
\text { camente }\end{array}$ & $\begin{array}{c}\text { Una vez } \\
\text { por semana }\end{array}$ & $\begin{array}{c}\text { Varias veces } \\
\text { por semana }\end{array}$ & Diariamente \\
\hline Escuchar música & $2 \%$ & $19 \%$ & $9 \%$ & $28 \%$ & $42 \%$ \\
\hline Ver la televisión & $4 \%$ & $9 \%$ & $7 \%$ & $16 \%$ & $63 \%$ \\
\hline Leer & $2 \%$ & $16 \%$ & $14 \%$ & $37 \%$ & $30 \%$ \\
\hline
\end{tabular}

Fuente: elaboración propia.

Cuadro 3. Frecuencia de realización de las diferentes actividades de ocio en la modalidad presencial

\begin{tabular}{|l|c|c|c|c|c|}
\hline & Nunca & $\begin{array}{c}\text { Esporádi- } \\
\text { camente }\end{array}$ & $\begin{array}{c}\text { Una vez } \\
\text { por semana }\end{array}$ & $\begin{array}{c}\text { Varias veces } \\
\text { por semana }\end{array}$ & Diariamente \\
\hline Reuniones con amigos & $0 \%$ & $20 \%$ & $28 \%$ & $40 \%$ & $12 \%$ \\
\hline Visitas culturales & $12 \%$ & $64 \%$ & $16 \%$ & $8 \%$ & $0 \%$ \\
\hline Pasear & $4 \%$ & $24 \%$ & $4 \%$ & $48 \%$ & $20 \%$ \\
\hline Practicar deportes & $8 \%$ & $32 \%$ & $16 \%$ & $28 \%$ & $16 \%$ \\
\hline Viajar & $8 \%$ & $76 \%$ & $8 \%$ & $0 \%$ & $8 \%$ \\
\hline Ir al cine & $16 \%$ & $76 \%$ & $4 \%$ & $0 \%$ & $4 \%$ \\
\hline Ir al teatro & $56 \%$ & $40 \%$ & $0 \%$ & $0 \%$ & $4 \%$ \\
\hline Escuchar música & $0 \%$ & $0 \%$ & $0 \%$ & $12 \%$ & $88 \%$ \\
\hline Ver la televisión & $0 \%$ & $20 \%$ & $4 \%$ & $16 \%$ & $60 \%$ \\
\hline Leer & $4 \%$ & $24 \%$ & $4 \%$ & $28 \%$ & $40 \%$ \\
\hline
\end{tabular}

Tras el análisis de los datos se observaron coincidencias en los porcentajes mayoritarios obtenidos en ambas modalidades. En primer lugar, en actividades tales como «Ir al teatro», la mayoría de los estudiantes respondieron «nunca». En cambio, en «Visitas culturales», "Viajar» e «Ir al cine», la respuesta fue "esporádicamente». Por último, en actividades como «Pasear», contestaron que «varias veces por semana», y «Ver la televisión», «diariamente». 
Se encontraron diferencias en lo referente a las reuniones con los amigos, practicar deportes, leer y escuchar música. En la modalidad semipresencial, el porcentaje más alto en lo que respecta a «Reuniones con amigos» se obtuvo en «una vez por semana», otorgando un valor prácticamente despreciable a los intervalos de mayor frecuencia (19\%) y un valor nulo a «diariamente». En cambio, los valores registrados en el grupo presencial fueron algo distintos, alcanzando los valores más elevados en frecuencias tales como «varias veces por semana», restándole valor al intervalo «una vez por semana». En este caso, el adverbio «diariamente» adquirió un valor del $12 \%$.

Por otra parte, la frecuencia mayoritaria registrada en la actividad «Practicar deportes», en el caso del alumnado semipresencial, resultó ser «varias veces por semana», seguida por «esporádicamente». Estos resultados se vieron invertidos en el caso de la modalidad presencial.

Por lo que respecta a «Leer», los porcentajes más altos se alcanzaron en la frecuencia de «varias veces por semana», en el grupo semipresencial, y, «diariamente», en el presencial.

Por último, aunque en la actividad «Escuchar música» los valores más altos en ambos grupos se registraron en «diariamente», cabe señalar la diferencia entre estos ( $42 \%$ en la modalidad semipresencial, frente a $88 \%$ en la modalidad presencial). En el grupo semipresencial las respuestas fueron más dispares, mientras que en el grupo presencial se limitaron a dos: «diariamente» $\mathrm{y}$ «varias veces por semana».

Las diferencias obtenidas en ambos grupos tras el estudio de la práctica de actividades de ocio podrían estar relacionadas con la edad del alumnado, así como con su situación familiar y laboral.

\subsection{Acceso al ciclo formativo}

En la figura 1 se presenta la distribución de los alumnos según el modo de acceso al ciclo formativo. En ambas modalidades, la vía de elección mayoritaria fue a través del título de educación secundaria obligatoria (ESO) o de un nivel académico superior. A diferencia de la modalidad presencial, en la modalidad semipresencial se observó un porcentaje de alumnos que accedieron al ciclo mediante la prueba de acceso a la universidad (PAU) para mayores de 25 años.

Es importante mencionar que existe otra vía de acceso a los ciclos formativos de grado medio: los programas de cualificación profesional inicial. Esta opción también fue valorada, pero no resultó seleccionada por ningún estudiante. 
Figura 1. Distribución porcentual de los alumnos matriculados en el ciclo formativo Emergencias Sanitarias según modo de acceso al mismo

a) Modalidad semipresencial

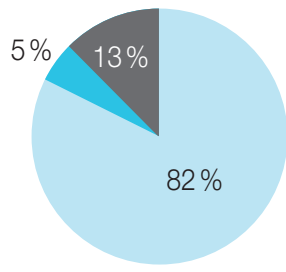

b) Modalidad presencial

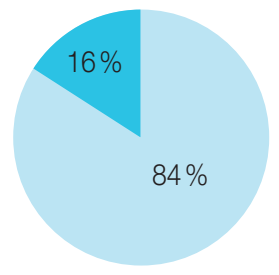

Título ESO o nivel académico superior.

Prueba de acceso.

PAU para mayores de 25 años.

Fuente: elaboración propia.

\subsection{Formación académica del alumno}

\subsubsection{Conocimiento de idiomas}

Se valoró el conocimiento de aspectos como el habla, la escritura y la comprensión de tres idiomas: valenciano, inglés y francés (véanse figuras 2, 3 y 4, respectivamente). Además, se ofreció la posibilidad de señalar el conocimiento de otros idiomas, tales como alemán, árabe, chino, italiano, rumano, ruso o cualquier otro.

Respecto al conocimiento de valenciano (véase figura 2), encontramos diferencias entre ambos grupos, observando un mayor número de estudiantes en la modalidad semipresencial que no tienen ningún conocimiento del idioma y un número menor en lo que respecta al nivel alto en cualquiera de las tres habilidades analizadas.

Figura 2. Niveles de comprensión, escritura y habla de valenciano de los alumnos del ciclo formativo Emergencias Sanitarias

a) Modalidad semipresencial

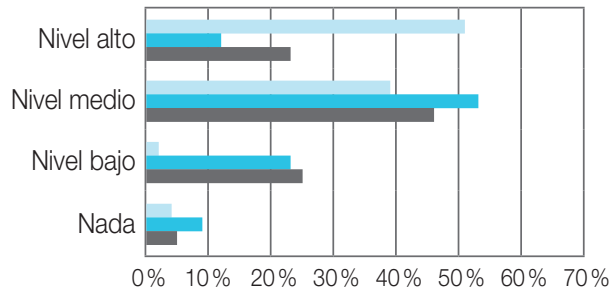

Comprensión. $\quad$ Escritura. Habla. b) Modalidad presencial

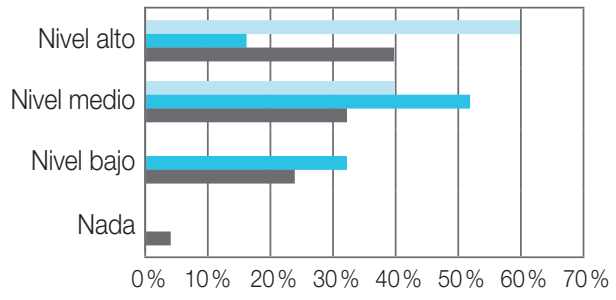

Fuente: elaboración propia. 
Respecto al nivel de inglés, ambos grupos se caracterizan por un nivel bajo, siendo mayor el porcentaje de alumnos con este nivel en la modalidad semipresencial (véase figura 3).

Figura 3. Niveles de comprensión, escritura y habla de inglés de los alumnos del ciclo formativo Emergencias Sanitarias

a) Modalidad semipresencial

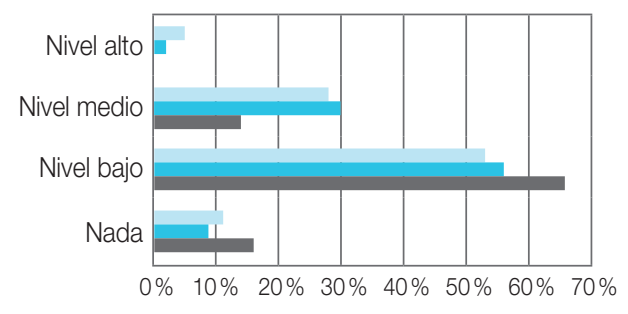

Comprensión. — Escritura. Habla. b) Modalidad presencial

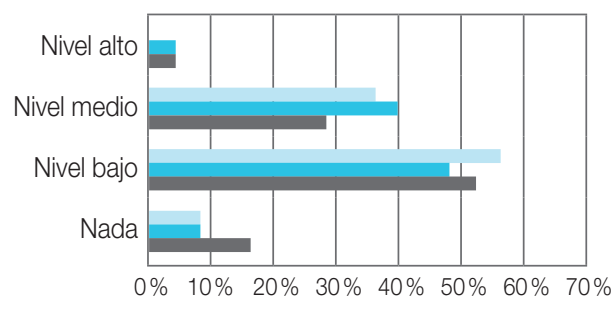

Fuente: elaboración propia.

En general, los alumnos de ambas modalidades no tienen ningún nivel de francés, siendo todavía más escaso en el grupo semipresencial (véase figura 4). Sin embargo, en la modalidad presencial se registran algunos estudiantes con nivel alto, a diferencia de la modalidad semipresencial, donde no existe este tipo de alumnado.

Figura 4. Niveles de comprensión, escritura y habla de francés de los alumnos del ciclo formativo Emergencias Sanitarias

a) Modalidad semipresencial

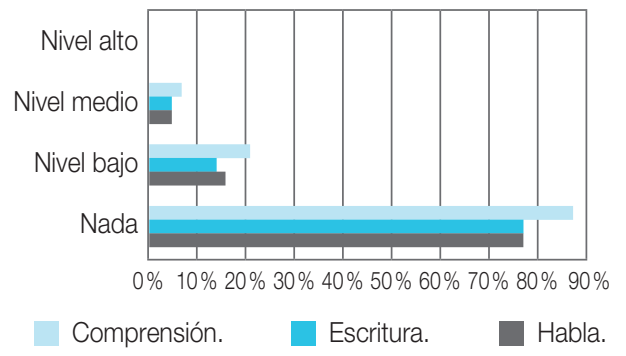

b) Modalidad presencial

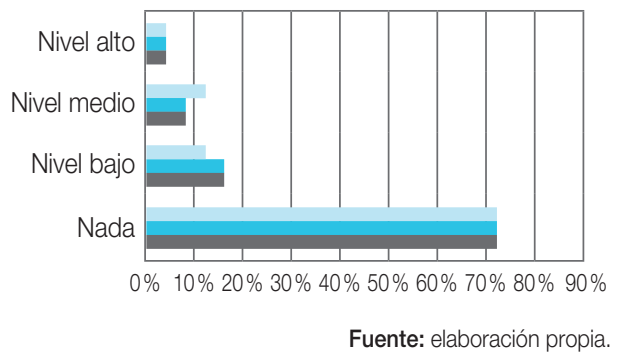

Respecto al conocimiento de otros idiomas, en la modalidad semipresencial, un $2 \%$ de los alumnos entrevistados indicaron su conocimiento de idiomas, tales como el alemán y otros no especificados en el listado, y un $5 \%$ de italiano. En cambio, en la modalidad presencial, se registró un $12 \%$ en italiano y un $4 \%$ en otros idiomas. 


\subsubsection{Conocimiento de informática}

Los resultados mostraron que prácticamente el $100 \%$ del alumnado sabe buscar información en internet, utilizar procesadores de texto y enviar y recibir correos. El $72 \%$ de los estudiantes hace uso de foros y chats y, aproximadamente, el $65 \%$ sabe usar hojas de cálculo. El porcentaje más bajo obtenido en ambos grupos hace referencia a la elaboración de una página web: $16 \%$, en la modalidad semipresencial, frente a $36 \%$, en la modalidad presencial.

\subsection{Interés por el ciclo formativo}

\subsubsection{Objetivos que se pretenden conseguir}

Mediante esta cuestión se intentó averiguar cuál había sido el motivo por el que el alumnado se había matriculado en este ciclo formativo. Los resultados obtenidos se muestran en la figura 5.

Figura 5. Distribución del alumnado de las modalidades semipresencial y presencial del ciclo formativo Emergencias Sanitarias según los objetivos que se pretenden alcanzar con la realización del mismo

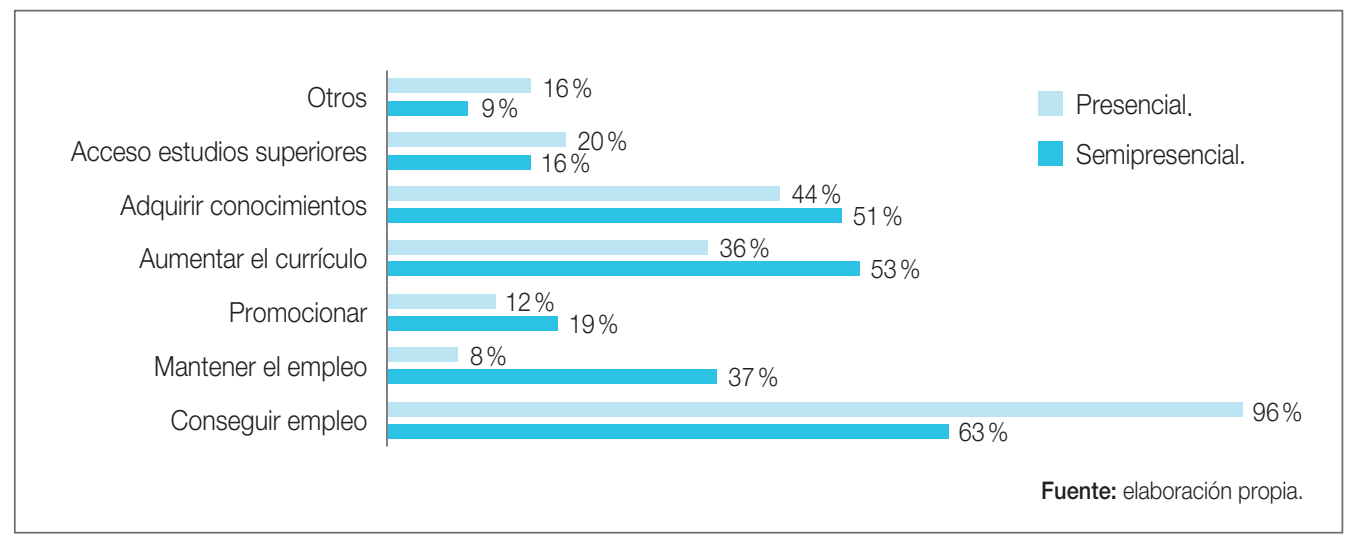

Se observa que el objetivo principal de prácticamente el $100 \%$ del alumnado presencial era «Conseguir empleo", adquiriendo también valores importantes los objetivos de «Adquirir conocimientos» y «Aumentar el currículum», pero siempre inferiores a los obtenidos en la modalidad semipresencial (44\% y $36 \%$, frente a $51 \%$ y $53 \%$, respectivamente). Los estudiantes de la modalidad presencial le dieron menos importancia al hecho de «Conseguir empleo» (63\%) y bastante más a «Promocionar» en él (19\%) a «Mantener el empleo» (37\%). 


\subsubsection{Interés por los módulos profesionales}

Se valoró el interés de los alumnos de cada grupo por los diferentes módulos profesionales impartidos en el primer curso del ciclo formativo de Emergencias Sanitarias. Los resultados se recogen en la figura 6 .

Figura 6. Distribución del interés del alumnado del ciclo formativo Emergencias Sanitarias según la modalidad y el módulo profesional

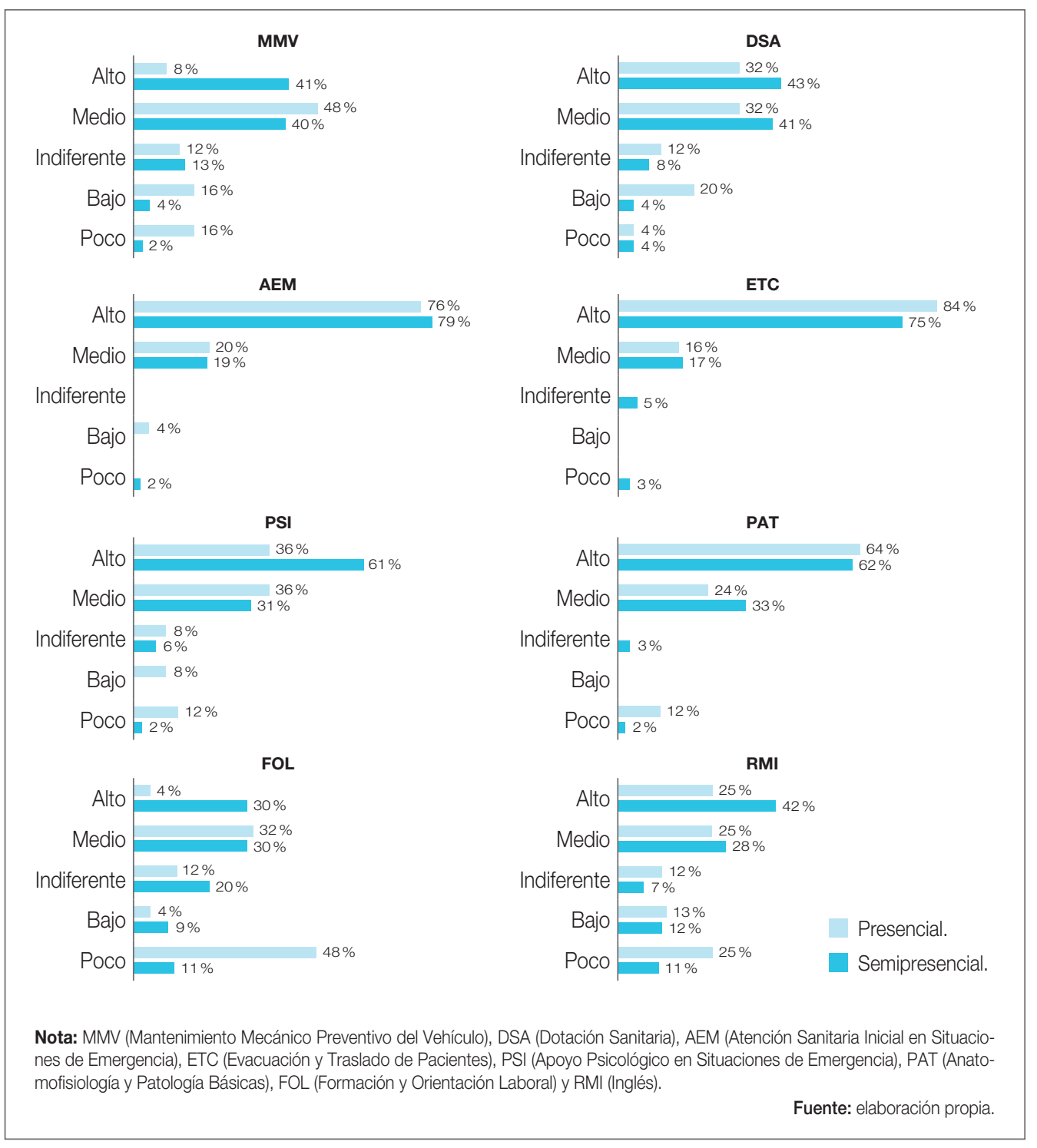


En ambas modalidades, los módulos que presentaron un interés más alto por parte del alumnado fueron Atención Sanitaria Inicial en Situaciones de Emergencia, Evacuación y Traslado de Pacientes y Anatomofisiología y Patología Básicas.

Por otra parte, se obtuvieron diferencias considerables entre el nivel de interés de los estudiantes hacia módulos como Dotación Sanitaria, Mantenimiento Mecánico Preventivo del Vehículo, Apoyo Psicológico en Situaciones de Emergencia, Formación y Orientación Laboral e Inglés, siendo en todos los casos superior en alumnos de la modalidad semipresencial.

\subsection{Rendimiento académico}

Se estudiaron las calificaciones obtenidas por los alumnos en cada uno de los módulos profesionales del primer curso del ciclo formativo. Los resultados expresados en porcentajes se presentan en la figura 7.

Figura 7. Distribución del alumnado de ambas modalidades del ciclo formativo Emergencias Sanitarias según las calificaciones obtenidas en los módulos profesionales cursados en primero

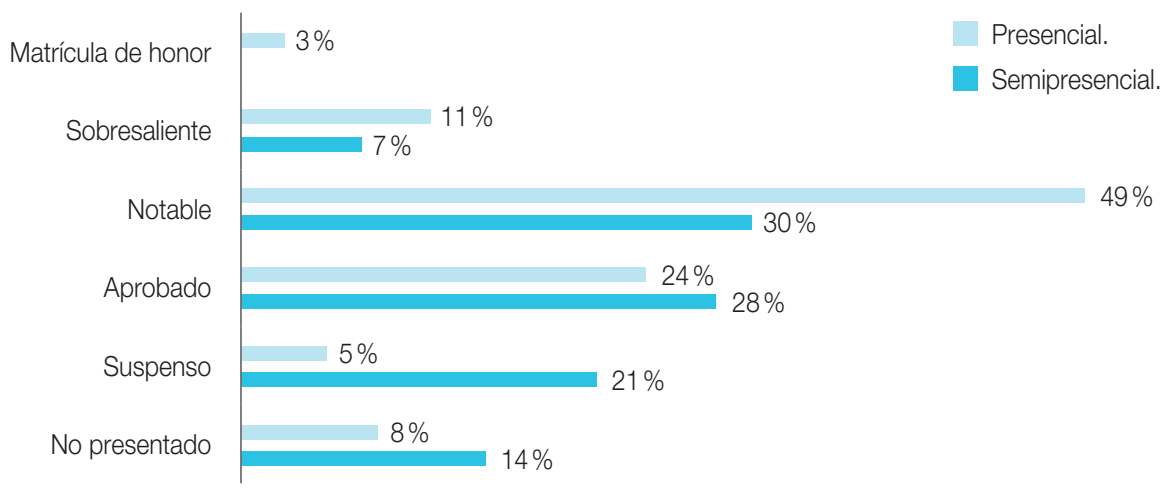

Fuente: elaboración propia.

Tanto en la modalidad semipresencial como en la presencial, el porcentaje más alto corresponde a la calificación de notable (30\% y $49 \%$, respectivamente). Este porcentaje es prácticamente el mismo que el de aprobados en el grupo semipresencial (28\%). Además, el porcentaje de suspensos y no presentados es mayor en la modalidad semipresencial, mientras que el de matrículas de honor y sobresalientes es más alto en la presencial. 


\section{Discusión y conclusiones}

La educación a distancia se está convirtiendo en un modelo pedagógico disruptivo del sistema educativo tradicional (García-Aretio, 2014). Espacios, tiempos, métodos, roles, alumnado y recursos están cambiando con esta modalidad de formación que potencia además la inclusión social y educativa (Cabero-Almenara, 2016). Esta modalidad está actualmente en auge, registrando año a año un incremento considerable en el número de alumnos matriculados. Sin embargo, el crecimiento no implica necesariamente calidad o adecuación. De hecho, en los últimos años se ha demostrado más de un $80 \%$ de fracaso en la gestión de estos cursos y más de un $60 \%$ de abandono por parte de los estudiantes (Cebrián, 2003).

En este trabajo se ha realizado un estudio comparativo del perfil de alumnado matriculado en la modalidad semipresencial y presencial de un mismo ciclo formativo. Para ello, se ha estudiado su perfil sociodemográfico, la forma de acceso al ciclo formativo, su interés por el mismo, así como su formación académica previa.

Los resultados obtenidos tras el estudio del perfil sociodemográfico de los estudiantes en ambas modalidades mostraron diferencias importantes respecto a género, edad, estado civil, tipo de domicilio, situación laboral y realización de actividades de ocio. En la modalidad semipresencial, el número de mujeres matriculadas es menor; en general, el alumnado es de mayor edad, existe un mayor porcentaje de casados/as, la mayoría poseen domicilio propio, compaginan el estudio con su trabajo y realizan actividades de entretenimiento con menor frecuencia. Estos resultados confirman la hipótesis inicial y prueban que este tipo de alumnado tiene más ocupaciones fuera del centro educativo y menor tiempo de dedicación al estudio, generalmente asociado a su situación familiar y laboral. En este sentido, numerosos autores afirman que este tipo de aprendizaje se está convirtiendo en una oportunidad de educación, especialmente para personas
Los resultados obtenidos tras el estudio del perfil sociodemográfico de los estudiantes de FP presencial y semipresencial mostraron diferencias importantes respecto a género, edad, estado civil, tipo de domicilio, situación laboral y realización de actividades de ocio

\section{El alumnado semipresencial tiene más ocupaciones fuera del centro educativo y menor tiempo de dedicación al estudio, generalmente asociado a su situación familiar y laboral} que tienen compromisos familiares y de trabajo, con problemas de tiempo y disponibilidad (García-Aretio, 2002). Además, y debido a su situación personal, estos alumnos parten de una motivación espontánea para el estudio, ya que asisten por voluntad propia, lo que genera mayores niveles de atención y trabajo autorregulado y más responsabilidad sobre sus actos (Florido y Florido, 2003; Meyer, 2002). 
Otro aspecto estudiado fue la formación académica previa de los estudiantes. Para ello, se les preguntó acerca de la forma de acceso al ciclo formativo, así como sobre su conocimiento de idiomas e informática. Se mostraron mayores niveles en el alumnado presencial que en el semipresencial en los tres idiomas valorados (valenciano, inglés y francés). Este hecho no parece ser debido al nivel de estudios de los estudiantes previo acceso al ciclo, pues en ambas modalidades la gran mayoría de los alumnos accedieron por título en ESO o de un nivel superior (82-84\%). Podría verse relacionado con el tiempo de dedicación, ya que, como ha quedado demostrado, el alumnado de la modalidad semipresencial tiene menos tiempo libre y más responsabilidades. Respecto a los conocimientos de informática, no se encontraron prácticamente diferencias, lo que confirma resultados obtenidos en estudios previos (Işik y Güler, 2012).

Para completar el análisis del perfil de los estudiantes se valoraron los objetivos que se pretendían conseguir en el ciclo formativo. Los resultados obtenidos mostraron que el objetivo que querían alcanzar con este curso, prácticamente el $100 \%$ de los estudiantes de la modalidad presencial, era conseguir trabajo. Resultado lógico, teniendo en cuenta que solo un $8 \%$ tenía una situación laboral activa. En el caso de la modalidad semipresencial, donde el porcentaje de personas activas es muy superior, esta opción también fue la mayoritaria. Por otra parte, aproximadamente un $20 \%$ de los estudiantes de ambas modalidades marcaron la opción de acceso a estudios superiores como objetivo, siendo este porcentaje ligeramente superior en los estudiantes de la modalidad presencial, hecho que parece razonable al tratarse de un alumnado más joven y con menos responsabilidades. Aunque cada vez existen más estudiantes que utilizan los ciclos formativos como vía de acceso a la universidad (Ibarz et al., 2012), los resultados obtenidos en este estudio demuestran que el principal objetivo del alumnado matriculado en formación profesional sigue siendo el de conseguir empleo. Si bien es cierto que este resultado podría estar condicionado por el hecho de que el ciclo formativo de estudio es un CFGM y que probablemente se modificaría si se tratara de un CFGS.

Por último, en el análisis del interés de los estudiantes por el ciclo formativo, se obtuvo que, en general, el alumnado del grupo semipresencial mostró un mayor interés por los contenidos recibidos. Estos datos podrían obtenerse como consecuencia de la edad (64\% mayor de 32 años), de las condiciones y de los intereses que impulsan a este tipo de alumnado a matricularse en este ciclo formativo. En este sentido, se han demostrado diferencias significativas en la motivación intrínseca de estudiantes universitarios en contextos presenciales y virtuales. Los alumnos de la modalidad online poseen una mayor motivación intrínseca, es decir, estudian por el placer y la satisfacción que uno experimenta mientras aprende (Rovai, Ponton, Wighting y Baker, 2007). Se ha demostrado que la motivación intrínseca está ligada a la autoconfianza y que los alumnos que presentan mayor autoconfianza se implican de forma más activa en el aprendizaje y rinden mejor (Camacho-Miñano y Del Campo, 2015). 
Directamente relacionado con el perfil del alumnado se estableció como otro objetivo definir el rendimiento académico de los estudiantes matriculados en ambas modalidades. Los resultados indican que las calificaciones obtenidas en la modalidad presencial, donde el $63 \%$ del alumnado obtiene una nota igual o superior a notable, son mayores a las registradas en la modalidad semipresencial, donde esta cifra es aproximadamente la mitad (37\%). Además, la modalidad presencial registra un menor porcentaje de suspensos y de no presentados que la modalidad semipresencial (13\%, frente a $35 \%$, respectivamente). La diferencia en el rendimiento académico podría estar relacionada con los diferentes perfiles de los estudiantes matriculados en cada modalidad. Por tanto, el mejor rendimiento académico obtenido en el alumnado de la modalidad presencial sería consecuencia de la ausencia de responsabilidades, del mayor tiempo de dedicación al estudio y de la interacción cara a cara con el profesor y los compañeros, necesaria para aprender ciertas habilidades sociales, como el manejo del liderazgo y el trabajo colaborativo. Estos resultados coinciden con los obtenidos por otros autores que sostienen que la formación presencial sigue siendo inmejorable por la cantidad de la interacción cara a cara con el profesor y los compañeros de clase, que es necesaria para aprender el manejo de cierto liderazgo y otras habilidades altamente colaborativas (Michell, 2001). Sin embargo, existen estudios que afirman que la formación semipresencial permite brindar una formación de calidad equivalente a los cursos presenciales y establecen ventajas, como el menor coste para el alumno y para la institución (Barberis, Bombelli y Roitman, 2004). En concreto, estudios previos han demostrado que el rendimiento académico de la modalidad semipresencial es satisfactorio y análogo al de la modalidad presencial (Griful, Gibert y Sallan, 2005). En este sentido, se ha observado que, con diseños pedagógicos rigurosos, sean en formato presencial o en modalidad a distancia, el rendimiento académico no difiere significativamente (García-Aretio, 2017).

Conviene señalar que en este trabajo se ha utilizado el concepto de «rendimiento académico» como sinónimo de «calificación obtenida». Así, no se ha considerado que, tal y como afirman varios autores, el rendimiento académico es un fenómeno multifactorial influido por factores tales como las metodologías de enseñanza utilizadas, la dificultad de emplear una enseñanza personalizada, los conceptos previos que tienen los alumnos, así como el nivel de pensamiento formal de los mismos (Benítez, Giménez y Osicka, 2000). En general, la educación a distancia presenta limitaciones en todos estos aspectos que podrían influir negativamente en el rendimiento académico del alumnado. En primer lugar, generalmente, se utilizan metodologías transmisivas inadecuadas, pues no se emplean pedagogías abiertas, horizontales y conectivas, adecuadas para el aprendizaje en línea. Asimismo, se utiliza 
la tecnología como elemento sustitutivo del libro impreso, en lugar de manejar herramientas para desarrollar experiencias didácticas imposibles de realizar con los medios anteriores (Cebreiro, Fernández y Arribia, 2017). Además, el nivel de personalización de las enseñanzas online es insuficiente. Teniendo en cuenta su perfil, cabe esperar que los estudiantes semipresenciales construyan sus conocimientos en función de experiencias y conocimientos anteriores, por lo que es más posible que cuestionen o no asimilen de forma inmediata el contenido aprendido (Moreno y Cárdenas, 2012). Sin embargo, habitualmente, la metodología empleada en ambas modalidades de aprendizaje es la misma, lo que pone en duda su adecuación. Por último, puesto que en la modalidad a distancia los estudiantes no participan de forma activa en el proceso de enseñanza-aprendizaje, no se fomenta la creación de conocimiento nuevo, ni tampoco se impulsa la innovación (Cebreiro et al., 2017). Por todo lo expuesto, aunque las calificaciones obtenidas en la modalidad presencial fueron más elevadas, resulta arriesgado afirmar que el rendimiento académico de este alumnado es superior sin antes considerar si el diseño pedagógico empleado es acertado o no.
Aunque las calificaciones obtenidas en la FP presencial fueron más elevadas, resulta arriesgado afirmar que el rendimiento académico de este alumnado es superior sin antes considerar si el diseño pedagógico empleado es acertado o no

Como principal conclusión, se puede afirmar que, en línea con lo expuesto por García-Aretio (2017), cuando los diseños pedagógicos son acertados, ambas modalidades de aprendizaje brindan una formación de calidad. Es previsible que los entornos virtuales de aprendizaje adquieran mucha más importancia en el futuro, pudiendo incluso llegar a desplazar a la educación presencial. Los avances en el campo de las TIC avizoran, cada vez más, entornos de aprendizaje virtuales donde cada día son más los centros que incorporan a su formación plataformas educativas que propician ambientes colaborativos, activos y creadores entre profesores y estudiantes. Sin embargo, en el caso de la FP, basada en la capacitación para el desarrollo de habilidades, donde el componente práctico es esencial, resulta bastante inviable pensar en esta opción. Efectivamente, aunque la educación a distancia ha mostrado numerosas ventajas, generalmente todavía no se ha conseguido una adecuada integración de los nuevos recursos didácticos y las estrategias de enseñanza-aprendizaje basadas en las TIC. Por ello, la formación del profesorado en este campo podría mejorar notablemente la calidad de esta modalidad de enseñanza, puesto que es el uso de los diseños pedagógicos adecuados lo que al final condiciona la calidad de la educación.

Cuando los diseños pedagógicos son acertados, ambas modalidades de aprendizaje brindan una formación de calidad

Efectivamente, aunque la educación a distancia ha mostrado numerosas ventajas, generalmente todavía no se ha conseguido una adecuada integración de los nuevos recursos didácticos y las estrategias de enseñanzaaprendizaje basadas en las TIC 


\section{Referencias bibliográficas}

Arkorful, V. y Abaidoo, N. (2015). The role of e-learning, advantages and disadvantages of its adoption in higher education. International Journal of Instructional Technology and Distance Learning, 12(1), 29-42.

Barberis, G., Bombelli, E. C. y Roitman, G. G. (2004). Estudio comparativo de los modelos de aprendizaje. A comparative study of two learning models. Revista de la Facultad de Agronomía, 24(2), 155-159.

Barker, K. (1986). Dilemmas at a distance. Assessment and Evaluation in Higher Education, 11(3), 219-230.

Benítez, M. E., Giménez, M. C. y Osicka, R. M. (2000). Las asignaturas pendientes y el rendimiento académico: ¿existe alguna relación? Recuperado de <https://studylib.es/doc/612 3451/las-asignaturas-pendientes-y-el-rendi miento-acad\%C3\%A9mico--\%C2\%BFe...> (consultado el 28 de abril de 2020).

Cabero-Almenara, J. (2016). La educación a distancia como estrategia de inclusión social y educativa. Revista Mexicana de Bachillerato a Distancia, 8(15), 138-147.

Camacho-Miñano, M. ${ }^{a}$ M. y Campo, C. del. (2015). Impacto de la motivación intrínseca en el rendimiento académico a través de trabajos voluntarios: un análisis empírico. Revista Complutense de Educación, 26(1), 67-80.

Cebreiro, B., Fernández, M. ${ }^{a}$ C. y Arribia, J. (2017). Formación profesional a distancia: Corriendo en la dirección equivocada. PíxelBit: Revista de Medios y Educación, 50, 65-76.

Cebrián, M. (2003). Innovar con tecnologías aplicadas a la docencia universitaria. En M. Cebrián (Coord.), Enseñanza virtual para la innovación universitaria (pp. 21-36). Madrid: Narcea Ediciones.
Chirino, E. (2008). Estudio del uso e impacto del sistema de gestión de enseñanza-aprendizaje MOODLE en la educación superior (Tesis doctoral). Universidad de Las Palmas de Gran Canaria, España. Recuperado de <https://accedacris.ulpgc.es/bitstream/ 10553/6308/4/0570674_00000_0001.pdf > (consultado el 2 de marzo de 2020).

Conselleria de Educación, Investigación, Cultura y Deporte. (2018). Resolución de 22 de mayo de 2018, de la Dirección General de Formación Profesional y Enseñanzas de Régimen Especial, por la que se establece el límite máximo de presencialidad exigible para el alumnado matriculado en determinados módulos profesionales de títulos de formación profesional en modalidad semipresencial o a distancia en la Comunitat Valenciana. Publicado en el DOGV núm. 8.307, de 31 de mayo de 2018. Recuperado de <http://www.dogv.gva.es/datos/ 2018/05/31/pdf/2018_5209.pdf> (consultado el 4 de febrero de 2020).

Felpeto-Guerrero, A., Rey-Iglesia, R., Fernández-Vázquez, A. y Garrote-Yáñez, D. (2015). Uso de plataformas e-learning y alfabetización digital en formación profesional a distancia. Revista de Estudios e Investigación en Psicología y Educación, 13, 163-167.

Florido, R. y Florido, M. (2003). La educación a distancia, sus retos y posibilidades. Centro de Referencia para la Educación Avanzada (CREA), 1, 1-9.

García-Aretio, L. (2002). La educación a distancia: de la teoría a la práctica. (2. ${ }^{a}$ ed.). Barcelona: Ariel.

García-Aretio, L. (2014). Bases, mediaciones y futuro de la educación a distancia en la sociedad digital. Madrid: Síntesis.

García-Aretio, L. (2017). Educación a distancia y virtual: calidad, disrupción, aprendizajes adaptativo y móvil. RIED: Revista Iberoamericana de Educación a Distancia, 20(2), 9-25. 
García, C. J. y Cabero, J. (2016). Evolución y estado actual del e-learning en la formación profesional española. RIED: Revista Iberoamericana de Educación a Distancia, 19(2), 167-191.

García, M. E., González, G., García, A. y Rodríguez, T. (2008). Modalidad de curso semipresencial. Aplicación en la asignatura Procesos Tecnológicos. Ingeniería Mecánica, 11(3), 47-52.

Gillbert, B. (2015). Online learning revealing the benefits and challenges. Education Masters, paper 303.

Griful, E., Gibert, J. y Sallán, J. M. ${ }^{a}$ (2005). Un modelo de blended learning en la Universidad Politécnica de Catalunya: la docencia semipresencial de la titulación de Ingeniería en Organización Industrial en la ETSEIT. IX Congreso de Ingeniería de Organización, Gijón.

Gros, B. y García-Peñalvo, F. J. (2016). Future trends in the design strategies and technological affordances of e-learning. En M. Spector, B. Lockee y M. Childress (Eds.), Learning, Design, and Technology. (pp. 1-23). Cham, Suiza: Springer.

Hannay, M. y Newvine, T. (2006). Perceptions of distance learning: a comparison of online and traditional learning. MERLOT Journal of Online Learning and Teaching, 2(1), 1-11.

Hemsley, C. (2002). Jones international university's focus on quality e-learning opens doors for students worldwide. Business Media, 39(9), 26-29.

Ibarz, M. U., Planas, J., Fachelli, S., Navarro, J. y Sánchez, A. (2012). ¿La expansión o limitación de la vía de acceso a la universidad a través de los CFGS tiene consecuencias en la equidad del sistema? La Sociología y los Retos de la Educación en la España Actual: XV Conferencia de Sociología de la Educación, Granada.

Işik, A. H. y Güler, i. (2012). Comprehensive comparison of traditional and distance learning master programs. Procedia-Social and Behavioral Sciences, 31(0), 120-123.

Merino, R. y Llosada, J. (2007). ¿Puede una reforma hacer que más jóvenes escojan formación profesional? Flujos e itinerarios de formación profesional de los jóvenes españoles. Témpora: Revista de Historia y Sociología de la Educación, 10, 215-244.

Merino, R., García, M., Casal, J. y Sánchez, A. (2011). Itinerarios formativos y laborales de los jóvenes graduados en formación profesional. Sobre algunos prejuicios en la formación profesional. Sociología del Trabajo, 72, 137-155.

Meyer, K. A. (2002). Quality in distance education: focus on on-line learning. ASHE-ERIC Higher Education Report. Jossey-Bass Higherand Adult Education Series, 29(4), 1-154.

Michell, L. (2001). E-learning methods offer a personalized approach. InfoWorld, 174-185.

Mikołajewska, E. y Mikołajewski, D. (2011). E-learning in the education of people with disabilities. Advances in Clinical and Experimental Medicine, 20(1), 103-109.

Ministerio de Educación y Formación Profesional, Subdirección General de Estadística y Estudios. (2009). Resúmenes generales curso 2007-2008, alumnado matriculado en enseñanzas no universitarias. Recuperado de <http://www.educacionyfp.gob.es/dam/ jcr:7a7859b5-ab26-410d-87dd-1ec4fa722c $3 c /$ resumen-pdf.pdfs (consultado el 6 de febrero de 2020).

Ministerio de Educación y Formación Profesional, Subdirección General de Estadística y Estudios. (2019). Estadística del alumnado de formación profesional, curso 2017-2018. Recuperado de <https://www.educacionyfp. gob.es/dam/jcr:a461da71-8247-4442-9ab1e0401fff8039/nota-17-18.pdf> (consultado el 6 de febrero de 2020).

Moodle. (2019). Statistics. Recuperado de $<$ https://stats.moodle.org/> (consultado el 17 de febrero de 2020). 


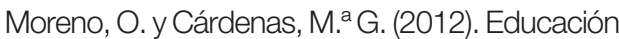
a distancia: nueva modalidad, nuevos alumnos. Perfiles Educativos, 34(136), 118-136.

Pema, E. y Mehay, S. (2012). Career effects of occupation-related vocational education: evidence from the military's internal labor market. Economics of Education Review, 31(5), 680-693.

Planas, J. (2012). ¿Qué es y para qué sirve hoy la formación profesional? De la VT (formación profesional) a la VET (formación y educación profesional). Revista de Sociología de la Educación-RASE, 5(1), 5-16.
Pollard, E. y Hillage, J. (2001). Exploring E-learning. Brighton, Inglaterra, Reino Unido: The Institutute for Employment Studies (IES)/Report 376.

Rovai, A. P., Ponton, M. K., Wighting, M. J. y Baker, J. D. (2007). A comparative analysis of student motivation in traditional classroom and e-learning courses. International Journal on E-learning, 6(3), 413.

Wheatley, B. y Greer, E. (1995). Interactive television: a new delivery system for a traditional reading course. Journal of Technology and Teacher Education, 3(4), 343-350.

\section{ANEXO}

\section{Cuestionario}

El objetivo del presente cuestionario es únicamente conocer el perfil del alumnado matriculado en el CFGM Técnico en Emergencias Sanitaras en las modalidades tanto presencial como semipresencial. Se trata de un cuestionario anónimo.

\section{Modalidad del ciclo formativo}

O Presencial

○ Semipresencial

\section{Sexo}

○ Mujer

O Hombre

\section{Edad}
○ 16-20 años
O 31-35 años
○ 21-25 años
○ 36-40 años
○ 26-30 años
○ 41-45 años

○ 46-50 años

$0>50$ años 
(cont.)

4. Estado civil
O Casado/a
O Viudo/a
O Soltero/a
O Separado/a

\section{Personas a cargo}

O Sí

O No

6. Tipo de domicilio durante el curso
O Paterno
Colegio mayor/Residencia universitaria
O Propio
O Piso compartido
O De otros familiares
O Hostal/Pensión

\section{Situación laboral actual}

¿Trabaja actualmente?
O Sí
O No

En caso afirmativo, ¿cuál es su jornada laboral?
O Reducida
O A turnos
O Continuada
O Nocturna
P Partida

¿El trabajo está relacionado con los estudios que está cursando?
O Sí
O No

8. ¿Con qué frecuencia realiza cada una de las siguientes actividades?

\begin{tabular}{|l|c|c|c|c|c|}
\hline & Nunca & $\begin{array}{c}\text { Esporádi- } \\
\text { camente }\end{array}$ & $\begin{array}{c}\text { Una vez por } \\
\text { semana }\end{array}$ & $\begin{array}{c}\text { Varias veces } \\
\text { por semana }\end{array}$ & Diariamente \\
\hline Reuniones con amigos & 0 & 0 & 0 & 0 & 0 \\
Visitas culturales & 0 & 0 & 0 & 0 & 0 \\
\hline
\end{tabular}


(cont.)

\begin{tabular}{|c|c|c|c|c|c|}
\hline & Nunca & $\begin{array}{l}\text { Esporádi- } \\
\text { camente }\end{array}$ & $\begin{array}{l}\text { Una vez por } \\
\text { semana }\end{array}$ & $\begin{array}{l}\text { Varias veces } \\
\text { por semana }\end{array}$ & Diariamente \\
\hline \multicolumn{6}{|l|}{ 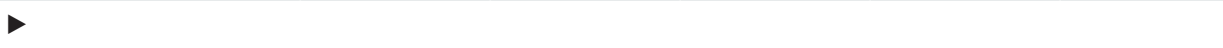 } \\
\hline Pasear & 0 & 0 & 0 & 0 & 0 \\
\hline Practicar deportes & 0 & 0 & O & $\bigcirc$ & $\bigcirc$ \\
\hline Viajar & 0 & 0 & 0 & 0 & 0 \\
\hline Ir al cine & 0 & 0 & 0 & $\bigcirc$ & $\bigcirc$ \\
\hline Ir al teatro & 0 & 0 & 0 & 0 & 0 \\
\hline Escuchar música & 0 & 0 & O & 0 & $\bigcirc$ \\
\hline Ver la televisión & 0 & 0 & 0 & 0 & 0 \\
\hline Leer & 0 & 0 & 0 & 0 & 0 \\
\hline
\end{tabular}

\section{Conocimiento de idiomas}

Valenciano

\begin{tabular}{l|c|c|c} 
& Habla & Escritura & Comprensión \\
\hline Nivel alto & 0 & 0 & 0 \\
Nivel medio & 0 & 0 & 0 \\
Nivel bajo & 0 & 0 & 0 \\
\hline
\end{tabular}

Inglés

\begin{tabular}{l|c|c|c} 
& Habla & Escritura & Comprensión \\
\hline Nivel alto & 0 & 0 & 0 \\
Nivel medio & 0 & 0 & 0 \\
Nivel bajo & 0 & 0 & 0 \\
\hline
\end{tabular}

\section{Francés}

\begin{tabular}{|c|c|c|c|}
\hline & Habla & Escritura & Comprensión \\
\hline Nivel alto & 0 & 0 & 0 \\
\hline Nivel medio & 0 & 0 & 0 \\
\hline Nivel bajo & 0 & 0 & 0 \\
\hline
\end{tabular}

\section{Otros idiomas}
O Alemán
O Chino
O Rumano
O Otros
○ Árabe
○ Italiano
O Ruso 
(cont.)

\section{Conocimiento sobre las nuevas tecnologías}

Sé utilizar los programas del Office (Microsoft Word, Excel, etc.)

- Envío y recibo correos electrónicos

- No tengo problemas para buscar información en internet

○ Sé elaborar una página web

U Utilizo los foros y los chats

\section{Modo de acceso al ciclo}

O Título de ESO o de un nivel académico superior

○ Prueba de acceso

- Prueba de acceso a la universidad para mayores de 25 años

○ Programa de cualificación profesional inicial (PCPI)

\section{2. ¿Qué pretende conseguir con este ciclo formativo?}
O Conseguir empleo
Adquirir conocimientos y cultura
○ Mantener el empleo
- Acceder a estudios superiores
- Promocionar en el trabajo
O Otros
- Aumentar el currículum

\section{Interés por las materias}

\begin{tabular}{|c|c|c|c|c|}
\hline & Nulo & Bajo & Medio & Alto \\
\hline Dotación Sanitaria & O & O & O & $\bigcirc$ \\
\hline Atención Sanitaria Inicial en Situaciones de Emergencias & O & O & O & 0 \\
\hline Evacuación y Traslado de Pacientes & $\bigcirc$ & $\bigcirc$ & $\bigcirc$ & ○ \\
\hline Apoyo Psicológico en Situaciones de Emergencia & $\bigcirc$ & 0 & $\bigcirc$ & O \\
\hline Anatomofisiología y Patología Básicas & $\bigcirc$ & $\bigcirc$ & $\bigcirc$ & ○ \\
\hline Mantenimiento Mecánico Preventivo del Vehículo & O & O & $\bigcirc$ & O \\
\hline Formación y Orientación Laboral & $\bigcirc$ & $\bigcirc$ & $\bigcirc$ & $\bigcirc$ \\
\hline Inglés & 0 & 0 & 0 & 0 \\
\hline
\end{tabular}




\section{Máster en}

\section{Dirección y Gestión de Centros Educativos}

Este máster oficial [60 créditos ECTS] tiene una duración normal de 12 meses.

Los miembros de equipos directivos y los gestores de instituciones educativas encuentran en la actualidad una necesidad apremiante de formación que les habilite para dar una adecuada respuesta a las complejas situaciones que acontecen diariamente en sus lugares de trabajo. Las demandas que la sociedad actual realiza a las instituciones educativas exigen una constante renovación tanto de los centros educativos como de la formación de los profesionales que trabajan en ellos.

Dirigido a: Titulados universitarios que quieran especializarse en el ámbito de la dirección y gestión de centros educativos. Este programa formativo no exige una experiencia previa en la materia, sino que pretende proporcionar a los participantes una formación completa para la dirección y gestión de los centros de forma progresiva y eficaz.

Objetivos: Capacitar a profesionales de primer nivel para el ejercicio eficaz de la función directiva y de gestión de centros educativos. Para ello, el máster pretende dotar al alumno de las competencias y herramientas necesarias para el trabajo en un equipo multidisciplinar de profesionales, así como para promover la calidad y la innovación dentro del sistema educativo.

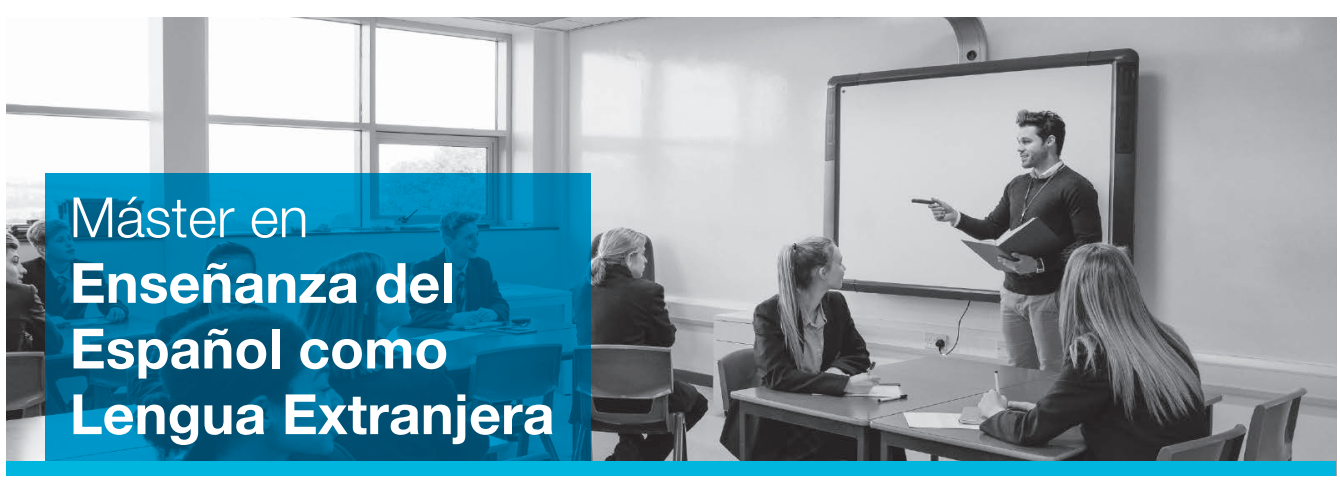

Este máster oficial [60 créditos ECTS] tiene una duración normal de 12 meses.

Dirigido a: Titulados universitarios en las distintas áreas de Lenguas Modernas, Filología, Lingüística, Traducción, Ciencias de la Educación, Humanidades, Pedagogía y Ciencias de la Comunicación y profesionales de las lenguas que deseen especializarse en la enseñanza del español como lengua extranjera.

Objetivos: Formar profesionales cualificados en el ámbito de la enseñanza del español como lengua extranjera, dotándolos de un perfil práctico y competitivo que los capacite para realizar adecuadamente y con garantía de éxito su labor profesional, facilitándoles su integración en un mercado laboral de enorme proyección internacional. 


\section{Nuestro sistema de enseñanza}

\section{/ Adaptados al mercado laboral. Adaptados a ti}

\section{Mucho más que una universidad a distancia}

La Universidad a Distancia de Madrid, UDIMA, es una institución educativa pensada y diseñada para cubrir las necesidades de las personas del siglo XXI: profesionales que demandan una universidad abierta y flexible, y que permita compatibilizar el estudio con las peculiaridades de cada estudiante, que buscan obtener una titulación universitaria reconocida oficialmente y de prestigio, adaptada a Europa y en contacto con el mundo de la empresa, y que facilite, además, una buena inserción laboral o mejore la que ya se posee.

\section{Campus virtual y sistema de evaluación}

El proceso de aprendizaje se desarrolla a través de las aulas virtuales de la universidad. Los estudiantes establecen una comunicación directa con sus profesores a través de los foros, el teléfono y otras herramientas telemáticas, como las clases en videoconferencia. Un sistema de evaluación continua, que utiliza las últimas herramientas tecnológicas en el ámbito de la didáctica, nos permite desarrollar una metodología activa que ayuda a nuestros estudiantes a «aprender haciendo».

\section{Profesorado}

En la UDIMA, la actuación de los docentes no se limita a la enseñanza, sino que también son «guías y facilitadores». La realización de un seguimiento académico pormenorizado y la personalización de la acción docente hacen de la UDIMA una comunidad de aprendizaje centrada en las personas.

\section{Materiales de enseñanza}

Nuestra editorial técnica se encarga de diseñar materiales específicamente creados para el aprendizaje online. Además, utilizamos recursos audiovisuales y material complementario de todo tipo que permiten aprovechar al máximo la experiencia formativa.

\section{Actividades de aprendizaje}

Los estudiantes van adquiriendo conocimientos a través de distintas actividades, tanto individuales como en grupo, para ir afianzando los contenidos.

\section{Test de autoevaluación}

Pruebas de evaluación online tipo test que, a modo de cuestionarios de autocomprobación, permiten que el estudiante pueda constatar los conocimientos adquiridos en el estudio previo de las unidades didácticas correspondientes.

\section{Actividades de evaluación continua}

Este tipo de actividades didácticas son pruebas de evaluación de tipo práctico: casos y trabajos basados en la búsqueda de información, el análisis de situación y la realización y presentación de informes.

\section{Exámenes presenciales}

Los exámenes finales semestrales son presenciales y con carácter obligatorio. Este tipo de prueba de evaluación permite verificar el cumplimiento de los objetivos de aprendizaje previstos en cada asignatura.

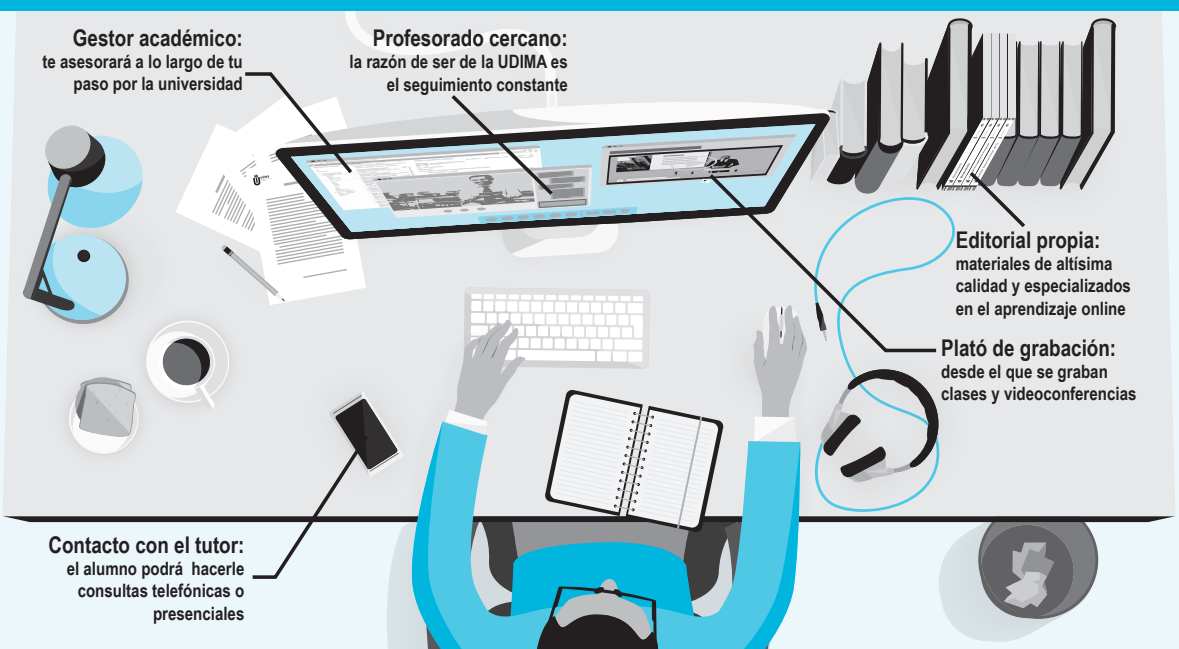




\section{¿Qué nos diferencia de otras Universidades online?}

La Universidad a Distancia de Madrid, UDIMA, está diseñada para cubrir las necesidades de las personas del siglo XXI: profesionales que demandan una titulación universitaria reconocida oficialmente y de prestigio, adaptada a Europa y en contacto con el mundo de la empresa, y que facilite, además, una buena inserción laboral o mejore la que ya se posee.

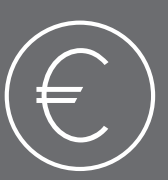

\section{Materiales incluidos}

El precio del crédito incluye todos los materiales necesarios para estudiar en la Universidad online más cercana. En la UDIMA siempre sabes lo que pagas. Sin sorpresas.
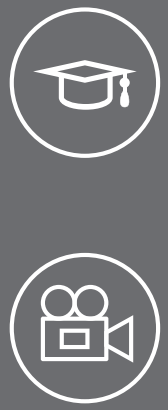

\section{Profesores especialistas}

Los profesores de la UDIMA no solo son expertos en la materia, sino también especialistas en la enseñanza online.

\section{Plató de grabación}

Contamos con un plató con las últimas tecnologías audiovisuales que nos permiten darte la máxima calidad en las clases en videoconferencia.
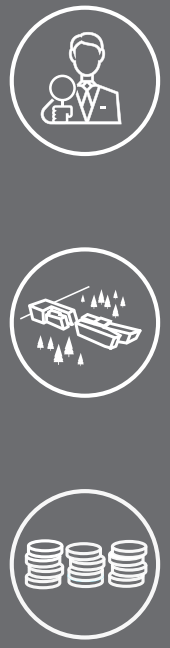

\section{Tutor personal}

Al inicio del Grado se te asignará un tutor personal que te acompañará todo el tiempo que estés con nosotros para que nunca te sientas solo.

\section{Campus propio}

Podrás venir a ver a los profesores a las instalaciones de Villalba. Nuestro campus ha ganado el prestigioso Premio Inmobiliario Internacional Asprima-SIMA.

\section{Pago fraccionado}

Para que el dinero no sea un impedimento, te ofrecemos la posibilidad de realizar el pago fraccionado o a través de financiación bancaria. Que estudiar sea tu única preocupación.

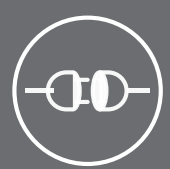

\section{Siempre conectados}

Nuestro compromiso es contestar en menos de $48 \mathrm{~h}$ a todas tus dudas, para que cumplir tus objetivos te sea más fácil. Siempre estaremos conectados.

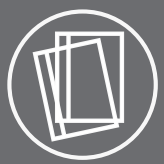

\section{Materiales adaptados}

Contamos con una Editorial propia que desarrolla los libros y carpetas especialmente diseñados para el aprendizaje online, que te llegarán a casa al principio de cada semestre.

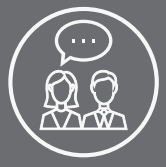

\section{Encuentros presenciales}

Realizamos talleres, conferencias y prácticas presenciales voluntarias que amplian el contenido de las asignaturas.

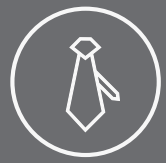

\section{Contacto con empresas}

Nuestra Bolsa de Trabajo y

Emprendedores te ofrece asesoría individualizada para que puedas potenciar tus cualidades y posicionarte como quieras en el mercado laboral.

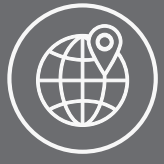

\section{Sedes de examen}

Estamos cerca de ti. Además de alrededor de toda España, contamos con sedes en Europa, Asia y América, con especial relevancia en Latinoamérica.

\section{Convocatoria en septiembre}

No es fácil compaginar el estudio con la vida personal y profesional. Por eso tenemos una convocatoria extra en septiembre. Tienes dos oportunidades al año de aprobar cada asignatura. 